\title{
ASSESSING INVESTIGATIVE SKILLS IN HISTORY: \\ A CASE STUDY FROM SCOTLAND
}

\section{Peter Hillis}

\section{Changes to the History Curriculum}

Recent changes in History syllabuses stress the importance of developing an investigative/enquiry method of learning involving the framing of questions, subsequent research and the presentation of findings. Scotland has made several attempts to assess this process alongside the end results and now uses an extended essay format in two important History courses which come at the end of Secondary schooling. This article discusses these various approaches to assessing investigative skills and evaluates the extended essay with particular reference to the comments of students and teachers. This analysis expands a previous article on the assessment of investigative skills which featured in this journal.(1)

The path which led to a greater emphasis on an enquiry method of learning began in the 1960s with trenchant criticisms of existing History Courses and teaching. In 1968, Mary Price argued that the aims of History teaching were seen as increasingly irrelevant while a concentration on British, largely English, History and didactic teaching methods made the subject "excruciating, dangerously dull".(2) The situation was little better in Scotland where John Fairley criticised "the desperate race through the centuries to examine fleetingly the vicissitudes of fortune that befell an interminable procession of Kings, barons and archbishops (which) often provided the School learner with nothing beyond a set of imperfectly understood facts and ill digested notions".(3) Similar criticisms were leveled at History teaching furth of 
Great Britain. Stuart Macintyre characterised History courses in Australia for concentrating on "the rote learning of events, names and places, and the absorption of moral homilies, in a triumphal catechism of the past".(4)

Change was gradual. Macintyre charted the reform of History education which began in the inter-war years with "an increasing emphasis on primary sources and the interpretation of historical evidence, and an increasing concern with causation and explanation".(5) A further development in the 1960s led to the study of periods and topics with consideration of alternative interpretations of the past. Students in the 1970 s and 1980 s were expected to work as historians through research involving the analysis and interpretation of evidence.

In Scotland, the increased use of primary and secondary sources received official recognition in 1970 with the introduction of the Alternative History Syllabuses for the middle and final stages of Secondary schooling. In these courses "each topic should be studied not only by the reading of textbooks, but also by reference to source material and by encouraging acquaintance with literary and visual material related to that period".(6) Eric Rothschild traced similar developments in the USA with the introduction in 1973 of the Document Based Question into the Advanced Placement Course with "the hope ... that High School teachers around the country would turn to primary sources in their classrooms"(7) Stovel has argued that the Document Based Question also helped students develop skills of analysis, interpretation and extended writing.(8) 
Eckstein and Noah argued that coursework in the form of investigations and projects raised important issues regarding assessment:

"Moving away from one-slot, time-bound examinations to assessments based on the results of work done over extended periods of time is likely to provide more authentic evidence of a students' capacities, but raises problems of grading standards, fairness and comparability that are very difficult to solve".(9)

According to Frith and Maclntosh the assessment of coursework and portfolios raised further concerns over weighting, support and resources. If coursework, which in History could involve a student research project, counted towards a final assessment then it must be weighted against other assessable elements. Assessment criteria for a research project must take into account the process and the product since an over emphasis on the latter could result in a "bulk and neatness syndrome" with "too much uncritical copying of irrelevant material".(10) Students undertake research projects over a relatively long period of time with most written up in class and/or for homework. Some students have access to plentiful resources and receive support from parents and teachers which may significantly influence the final grading. These students are placed at a considerable advantage by a supportive home environment. Therefore, investigative skills set a demanding challenge. Is it possible to devise a system for assessing research skills in ways which ensure that the student's own work receives an appropriate mark and/or grade? A successful answer would help strengthen investigative skills within the curriculum.

This article discusses how Scotland has attempted to square this apparent circle through an at times fraught process which has led from investigations to examination questions and on into the extended essay/extended response. Scotland would not 
claim originality in these areas since both the French and International Baccalaureates include extended essays. Nonetheless, the lessons learned in Scotland many help other countries devise their own forms of assessment.

In Scotland, students begin their formal education by entering Primary School at the age of five. Primary schooling continues from Primary 1 until Primary 7 when students move to Secondary School which comprises six stages, Secondary 1 Secondary 6, although some students leave at the end of Secondary 4 or 5 having reached the statutory leaving age of sixteen years. History remains a compulsory subject up until the end of Secondary 2 when it competes against the other social subjects for students. Approximately one third of students opt for History in Secondary 3 and 4 , but this proportion drops when a further choice of subjects is made at the end of Secondary 4.

History is taught as a compulsory subject from Primary 1 to Secondary 2 under the umbrella of Environmental Studies with teachers relatively free to choose topics as long as these satisfy general guidelines regarding chronological and geographical coverage. In Secondary 1 and 2, History generally receives one hour per week in a school's timetable. In Secondary 3 and 4, the course becomes more prescriptive with a national syllabus referred to as Standard Grade History following the pattern of Standard Grades in each subject area. Standard Grades divide into three ability levels: Foundation; General and Credit which in turn leads onto further levels in Secondary 5 and 6. These levels comprise: Access; Intermediate 1; Intermediate 2; Higher and Advanced Higher. Teachers normally allocate students to the appropriate course level based on past performance. For example, a student with a Credit level 
award at Standard Grade studies Higher in Secondary 5 and possibly Advanced Higher in Secondary 6. A General level student at Standard Grade would normally study Intermediate 2 in Secondary 5 and possibly Higher in Secondary 6. Parents and students usually accept their teacher's decision regarding course level, but in a minority of cases this is challenged to ensure that students study Higher level, recognised as 'the gold standard' for University entrance.

The time allocation in Secondary 1 and 2 of one hour per week increases to three hours for Standard Grade and five to six hours for Higher. In History, the final award at Standard Grade, Intermediate, Higher and Advanced Higher is determined by performance in externally assessed examinations and essays/dissertations. Awards at Standard Grade range from 1 to 7 and at Higher from A to D. Other subjects, for example English and Art, include teacher assessed course work in their final awards, but the equivalent practice in History caused significant difficulties. This leads into a discussion of Scotland's experience of assessing investigative skills.

\section{Scotland's Experience of Assessing Investigative Skills}

This began in 1983 with the introduction of Standard Grade History, the national course for students opting for History in the middle years of Secondary School (student ages 14-16 years). Within this course students had to complete a Historical Investigation which counted towards one third of the final grade. The Investigation brought together the skills of framing questions, analysing evidence and presenting findings. Other elements were that:

1. Investigations had to be based on an issue which led to a conclusion; 
2. The issue had to relate to developments in Scottish History or to connections between Scotland and other countries;

3. Research included reference to primary and secondary sources;

4. Students had to retain evidence of planning collecting evidence and presenting the conclusion.

In almost every case the final product was a written report with a recommended length set at between $400-1,200$ words. Class teachers marked the final report with samples sent for external moderation by the then Scottish Examination Board.

Students completed investigations during class time and for homework with the expectation that they would utilise libraries and museums. The amount of time given over to the Investigation varied from school to school, but was anything up to eight weeks, or approximately fourteen per cent of the teaching time allocated to History. However, the time spent working on the Investigation at home was without limit.

Investigations covered a plethora of issues, but one illustrates many strengths and weaknesses of the innovation. It was not untypical. The student framed the following issue:

"The Lifestyle and Working Life of a Buchan Farm Worker has Improved Since the Nineteenth Century".

This study involved the student in several weeks' work visiting the local library, interviewing farmworkers, collecting photographs and recording music and poems. Much of the subsequent information could have been used on University Undergraduate Courses. The final report, which exceeded 4,000 words, was structured to include an introduction, several chapters and a conclusion. Needless 
to say it received the top grade and clearly demonstrated investigative skills in action from framing the hypothesis through to the conclusion. The title of this Investigation gave scope for an active process of working towards a conclusion, but for many pupils framing the question or issue proved a difficult task requiring considerable teacher support. This support had to be taken into account when teachers graded their pupils' work, a penalty which perversely acted as a disincentive to a key component of effective teaching and learning. Project type titles such as 'Robert the Bruce' and 'The History of Glasgow Rangers' often resulted in descriptive and narrative accounts rather than investigations based on analysis and debate. The considerable word count for the Buchan report exceeded the recommended total and emphasised the time and effort involved in research and writing. Moreover, students were confronted with the requirement to complete folios and investigations in many other subjects which resulted in excessive expectations. The failure to consider the overall impact of educational change on student workload has been a recurring weakness in Scottish education during the 1980s and 1990s.

Investigations placed pressure on teachers who had to manage the process from the choice of issue through to marking the final report. Managing resources proved a significant challenge to ensure that pupils had equity of access to primary and secondary sources. The implicit assumption that over 20,000 History students would burrow feverishly away in archives and libraries was unrealistic and impracticable. In fact, a common sight at Glasgow City Archive was mothers requesting documents on nineteenth century housing conditions while their sons/daughters stood several paces behind with a look of abject embarrassment on their faces. 
Frith and Maclntosh highlighted the conflict which often arose in coursework when the teacher was both tutor and assessor.(11) Until the advent of Standard Grade History, the marks given by teachers during the course had no bearing on the final award which resulted from performance in an external examination. However, the teacher's grade for the Investigation counted towards the final course award which placed teachers in a difficult situation especially when, as noted above, tutorial support could reduce the marks allocated. Moreover, teachers, parents and students frequently raised questions regarding authenticity and fairness. Many students received help from parents and/or tutors to the extent that with some Investigations the authorship was open to question while some top-rated Investigations began to be sold on the open market. Consequently, the Investigation favoured students from more affluent and supportive home backgrounds.

Scotland's experience with the Historical Investigation raised many of the difficulties associated with coursework and its assessment in such areas as resources, workload, the teacher's role, authenticity and fairness. Authenticity and fairness became key areas of concern resulting in Investigations being replaced by questions in the external examination. These did not meet the demands of new History since students were not involved in an active and enquiry method of learning. Up to this point, therefore, Scotland fails to provide a realistic approach to the assessment of investigative skills. Nonetheless, developments in Secondary 5 and 6 with Intermediate and Higher provide a more robust model. 
External assessments at Intermediate 2 and Higher require students to write essays, answer document based questions and complete an extended essay (Higher) or extended response (Intermediate 2). The extended essay/response are very similar tasks, despite the different nomenclature, and will be referred to hereafter as the extended essay. The extended essay and the document based question test different skills. The document based paper examines students' ability to analyse, evaluate, interpret and place in context five sources relating to a chosen Special Topic. The following example comes from the 2004 examination for Special Topic 8, The Origins and Development of the Cold War 1945-1985:

Source C: from A. Dobson and S. Marsh, US Foreign Policy since 1945 (2001)

"The Kennedy administration oversaw a major change in the nature of the Cold War and a turning point in containment policy. The development of Mutual Assured Destruction (MAD) shifted the emphasis from outright victory to that of managing an enduring balance between East and West. The new "logic" of the Cold War was for a peaceful resolution and this, for US policymakers, signalled the end of the drive for victory through military strength. $M A D$, as the Cuban missile crisis demonstrated in 1962, generated unacceptable levels of brinkmanship. Instead, the emphasis was on collaboration with the Kremlin to assure system stability. Core US-Soviet relations had to be kept in mutually accepted balance at the same time that their intense competition was fought out on the edges of the Cold War, such as in Vietnam".

The question based on this source was:

How far do you agree with the views in Source $\mathbf{C}$ on the changing character of the Cold War from the early 1960s onwards? (6 marks)

The marking instructions demonstrate that this answer requires reference to the source and to recalled knowledge, but it is not a test of investigative/research skills. 
Marking Instructions for the question: How far do you agree with the views in Source C on the changing character of the Cold War from the early 1960s onwards? (6)

The candidate makes a judgement on the views in Source $C$ in terms of:

From Source: Major changes in nature of Cold War during Kennedy years.

Mutually Assured Destruction resulted in efforts to maintain the east-west balance, rather than try to achieve victory; there was a need to work for peaceful solutions to crises, rather than military strength.

Cuban Missile Crisis illustrated risks of confrontation.

Collaboration with Russians to maintain stability produced balanced US/Soviet relations. Conflict restricted to edges of Cold War, as in Vietnam.

Aim now not to lose, rather than to win.

From Recall: Nuclear arms race from 1960 onwards - ABMs, ICBMs, SLBMs (Polaris). MAD made victory in all out war no longer attainable as the destruction of both sides was likely.

Therefore, the aim in foreign policy was to avoid conflicts where possible, and cooperate to reduce tension.

Cuban Missile Crisis details - illustrated frightful risks of direct confrontation. Attempts to reduce tension in years following Cuban crisis. 
"Hot line" established between USA and USSR - telephone link to enable direct contact between Superpowers.

1963 Test Ban Treaty—limits nuclear testing.

Later 1960s, start of SALT talks on limiting nuclear weapons.

SALT Treaty 1972—start to limiting pace of arms race.

Non-proliferation agreement.

Candidates may refer to the Vietnam War - very serious and bloody conflict, but no confrontation between Superpowers.

Détente in 1970s - significant improvements in relations between USA and USSR.

Marks: 1-2 Selects relevant evidence from the source and/or from recalled knowledge but without making the required evaluation.

3-4 Selects relevant evidence from the source and uses limited recalled knowledge to inform a basic evaluation in terms of the question.

5-6 Establishes the main points in the source and uses recalled knowledge to evaluate it and reach an appropriate conclusion.

The extended essay is an investigative task which counts towards 30 out of the 110 marks (twenty-seven percent) of the final award. It is normally completed approximately two-thirds of the way through the course within a two to three week 
period combining school and home-based study. Students base their essay on an issue of their choice, but it must be drawn from one of the contexts chosen for study in the course. The issues devised by students cover a very wide range of themes and topics. For example:

- $\quad$ How effective were the Suffragettes in obtaining the vote for women by $1918 ?$

- To what extent was Louis XIV of France an absolute monarch?

- How effective was the National Insurance Act of 1911 in helping the poor?

- $\quad$ Explain the importance of non-violent protests in the struggle for Civil Rights in the USA between 1950-1970.

- Was Britain justified in following a policy of appeasement towards Hitler up to 1939 ?

Prior to writing the essay, students research the chosen issue using a range of sources and then prepare an outline plan of 200 words with excessive length penalised by a loss of marks. Students take this plan into a classroom where the essay is written within a continuous period of two hours under the supervision of a teacher. The essay is marked outwith the school through the Scottish Qualifications Authority using pre-determined and publicised criteria. The criteria for an 'A' pass illustrate the application of investigative skills to the extended essay:

\section{Band A: $\quad$ 21-30 marks}

The evidence presented will be indicative of substantial research of a variety of sources relevant to the issue.

The line of argument will be well-developed, clear and coherent throughout the essay. There will be an awareness of different possible interpretations of the issue. This may be supported by evaluation of sources for features such as reliability, bias and consistency.

There will be a fluent presentation of the conclusion, arising in a logical manner from the argument presented. 
External marking of the extended essays raises issues concerning reliability. Robert Wood argued that the reliability of grades is "the bottom line of the examining system; all other reliabilities, of markers, teachers and items, feed in to produce outcomes which are more or less reliable and therefore just".(12) Wood outlined a range of strategies which examination boards could use to ensure reliability, but he acknowledged that "none of them will ever completely solve" the issue.(13) The Scottish Qualifications Authority follows much of Wood's advice to make the final grades reliable and a fair reflection of the candidate's ability. Markers are selected for their experience of presenting students in the relevant course and work under the guidance of a Principal Assessor and examining team. Before marking commences, the examining team select a range of essays and decide on the mark and grade. These form the basis for discussion at the Markers' Meeting where general agreement on standards is reached. Markers receive a random allocation of scripts to avoid a disproportionate number from a particular type of centre since "the overall calibre of scripts seen is bound to have an effect on marking behaviour".(14) Markers are encouraged to regularly re-mark scripts to monitor their own consistency and reliability. At the end of the marking period the examining team check a sample of each marker's allocated scripts for consistency and reliability adding, where necessary, a weighting to the given marks. In situations where the marking proves inconsistent and unreliable the examining team re-mark every script allocated to the marker. However, this is a rare procedure only applied, for example, to two markers between 2000 and 2003 at Intermediate 2 . The final stage of examining takes place after centres and students receive their grades. Since appeals can be submitted for results which centres consider do no accurately reflect the standards of performance achieved in course work. Centres support each appeal with evidence of course work 
which the examining team considers alongside performance in the external examination.

The impact of the extended essay can be measured at four levels: a national survey of teacher opinion; a smaller sample of student attitudes; examiner and Principal Assessor reports and the marks/grades allocated. In Autumn 2002, the Scottish Qualifications Authority conducted a national review on aspects of assessment within the upper secondary curriculum. This review included questions on the extended essay at Higher and the extended response at Intermediate 2. Schools were asked to record whether they strongly agreed, agreed, disagreed or strongly disagreed with the statement that the extended essay/response should be retained. Schools were also free to make general comments on the essay/response. Four hundred questionnaires were distributed with 225 returned.

Student perceptions of the extended essay were gauged through a small survey carried out in ten schools with 205 students. A questionnaire asked students to record when they had carried out the planning and research stages and whether they strongly agreed, agreed, disagreed or strongly disagreed with the proposition that the extended essay should be retained.

Students placed in rank order of importance nine positive and six negative features of the extended essay. These positive and negative features included those noted by teachers in their questionnaire, but students could also add their own perceptions of the advantages and disadvantages to those given in the questionnaire. Students were divided into two groups. Group 1 was students who had just completed the 
extended essay in March 2003 and who still had to sit the final course examination. Group 2 was students who completed the essay in March 2002, and were studying Advanced Higher History in Session 2002-2003.

The analysis of marks and grades concentrates on overall mean scores since the Scottish Qualifications Authority does not publish detailed results for all candidates. Therefore, it is not possible to analyse the influence of factors such as School and gender. This also precludes a detailed comparison of individual candidate's results between the extended essay and the external examination.

\section{Teacher Evaluation of the Extended Essay}

Figures 1 and 2 show strong support for the extended essay and response.

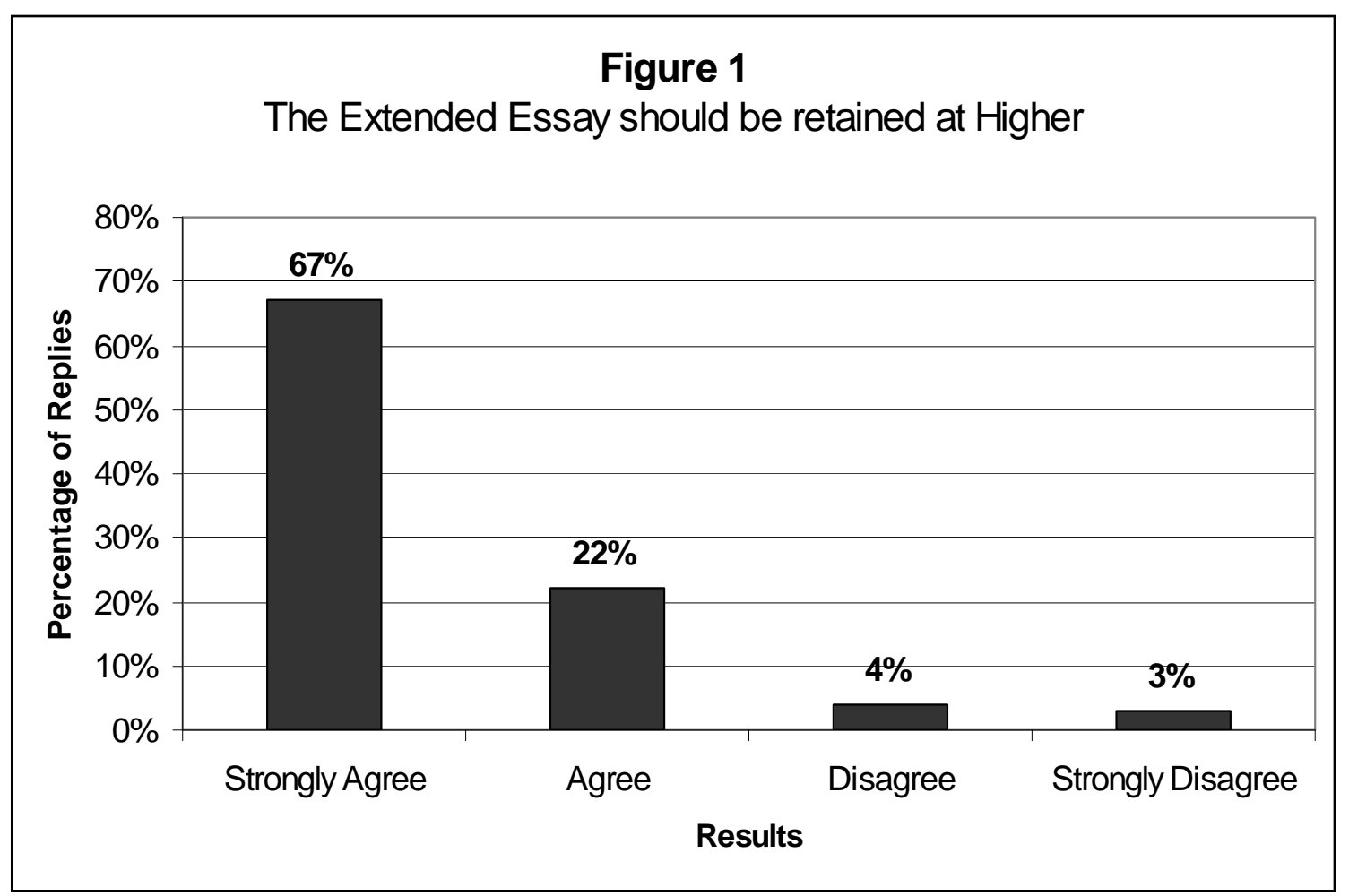


The five most common reasons for supporting the extended essay were in order of priority:

1. The essay develops independent research skills;

2. It motivated students by counting towards their final award;

3. Students welcomed the freedom to choose an issue and felt they had ownership of the process and final product;

4. The process helped prepare students for Higher Education;

5. $\quad$ The extended essay represented students' best work.

Responses either disagreeing or strongly disagreeing with the extended essay gave as reasons:

1. Difficult for average/lower ability students;

2. Places an additional demand on students;

3. Out of line with assessment in other Social Subjects;

4. Lack of feedback from the Scottish Qualifications Authority on student performance;

5. Places additional demands on a course in which it is difficult to cover all the necessary content.

Figure 2

The Extended Response should be retained at Intermediate 2

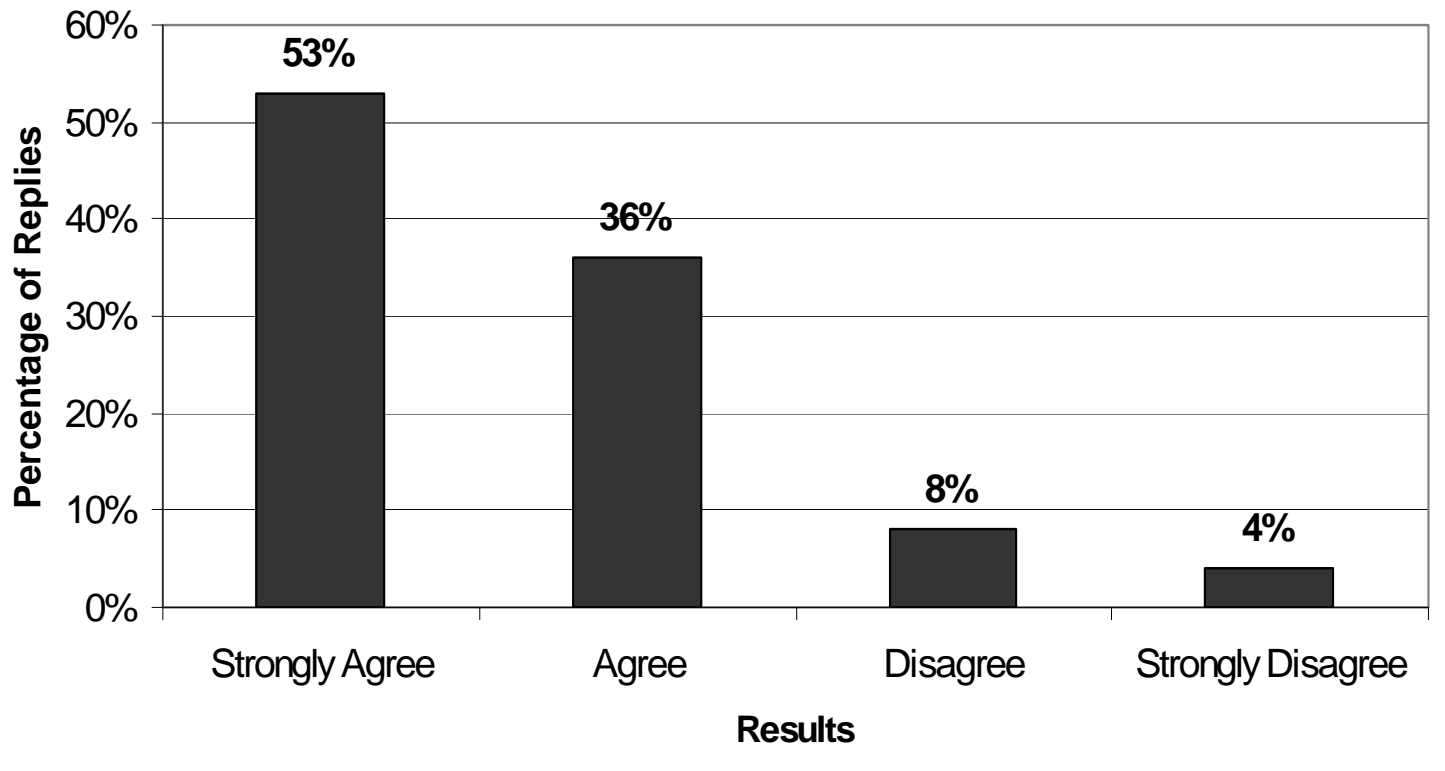


Reasons given for supporting the extended response included its beneficial role in preparing students for the Higher course, the development of research and writing skills, the freedom for pupils to choose their own topic and that it represented students' best work. The concerns at Intermediate 2 mirrored those for the extended essay at Higher. However, it is important to note that those either disagreeing or strongly disagreeing represented a very small proportion of returns.

\section{Student Evaluations}

Group 1, students completing the essay in 2003 , and Group 2, students who had completed the essay in 2002, recorded strong support for this part of the course. Both groups supported retention of the extended essay with strongest backing coming from Group 2. Forty-two percent of Group 2 strongly agreed with the proposition that the essay should be retained compared to twenty-two percent in Group 1. Nonetheless, sixty-six percent of Group 1 agreed that the essay should be retained. Five per cent of students in Group 1 strongly disagreed with the proposition in contrast to zero percent in Group 2.

Over eighty percent of Groups 1 and 2 carried out the planning and research stages in school and for homework, with broadly similar agreement also evident in results for the essay's positive features as illustrated in Figures 3 and 4 . 


\section{Figure 3}

Group 1

Positive Features of the Extended Essay

Percentage of pupils rating specific aspects of the Extended Essay within the top three positive features

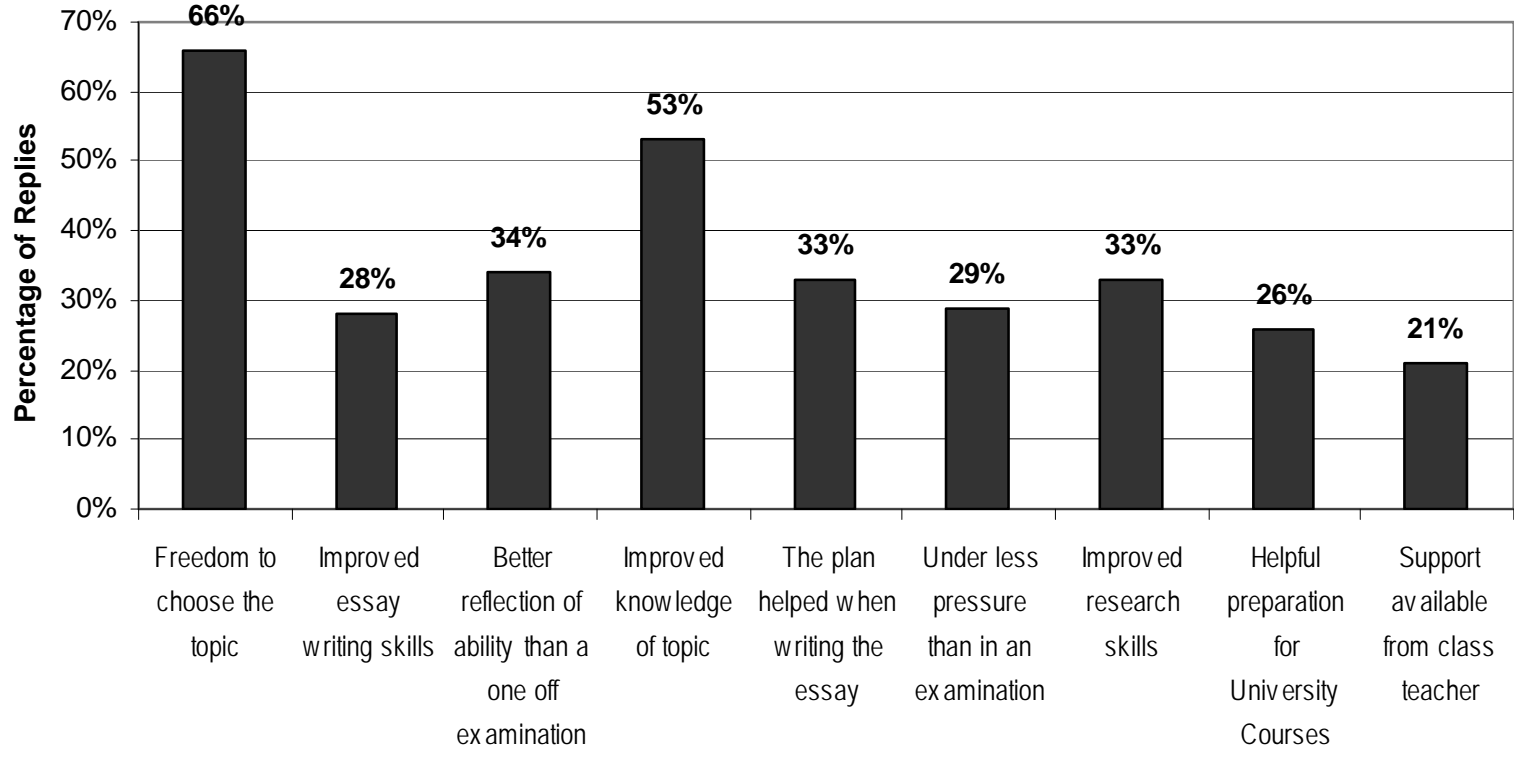

Positive Features 


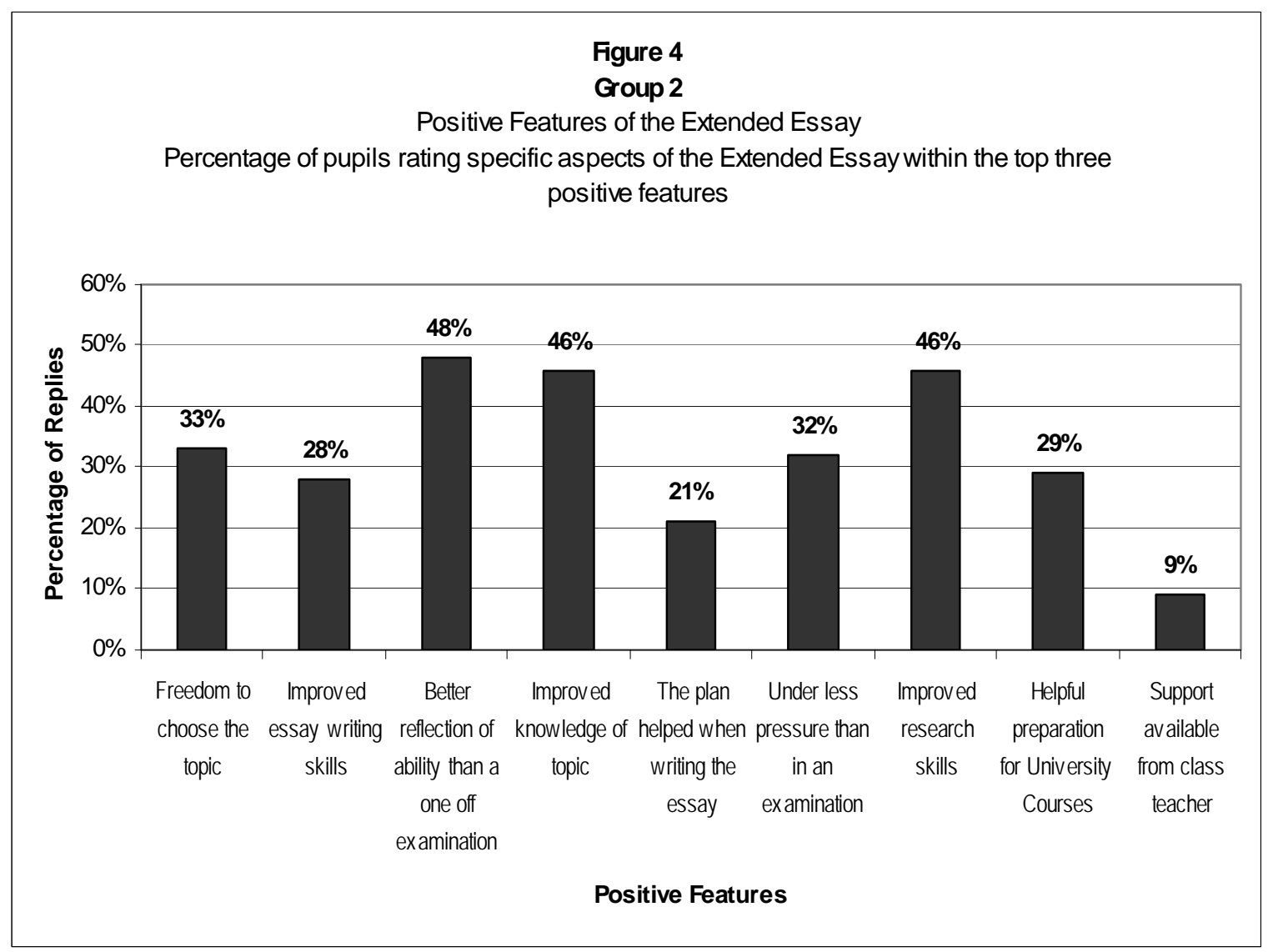

Both groups highly rated the freedom to choose a topic alongside the subsequent improved knowledge and research skills. Group 2, however, gave a significantly higher rating to the essay being a better reflection of their ability than a one-off examination, a finding which is largely explained by the fact that Group 1 had still to complete the course and sit the examination. In their general comments on the positive features, Group 2 emphasised the value of the essay in preparation for the Dissertation at Advanced higher which also explains this group's stronger overall support for retention of the essay. Other advantages given by students were that the freedom to choose a topic "allowed me to formulate my own opinions", "self-directed learning proved satisfying" and that it "showed the importance of study and preparedness and the value it has in helping achieve a higher grade". 
Despite the strong support for the extended essay, students were not uncritical and noted some negative features. Figures 5 and 6 illustrate the ratings given to the six negative features in the questionnaire.
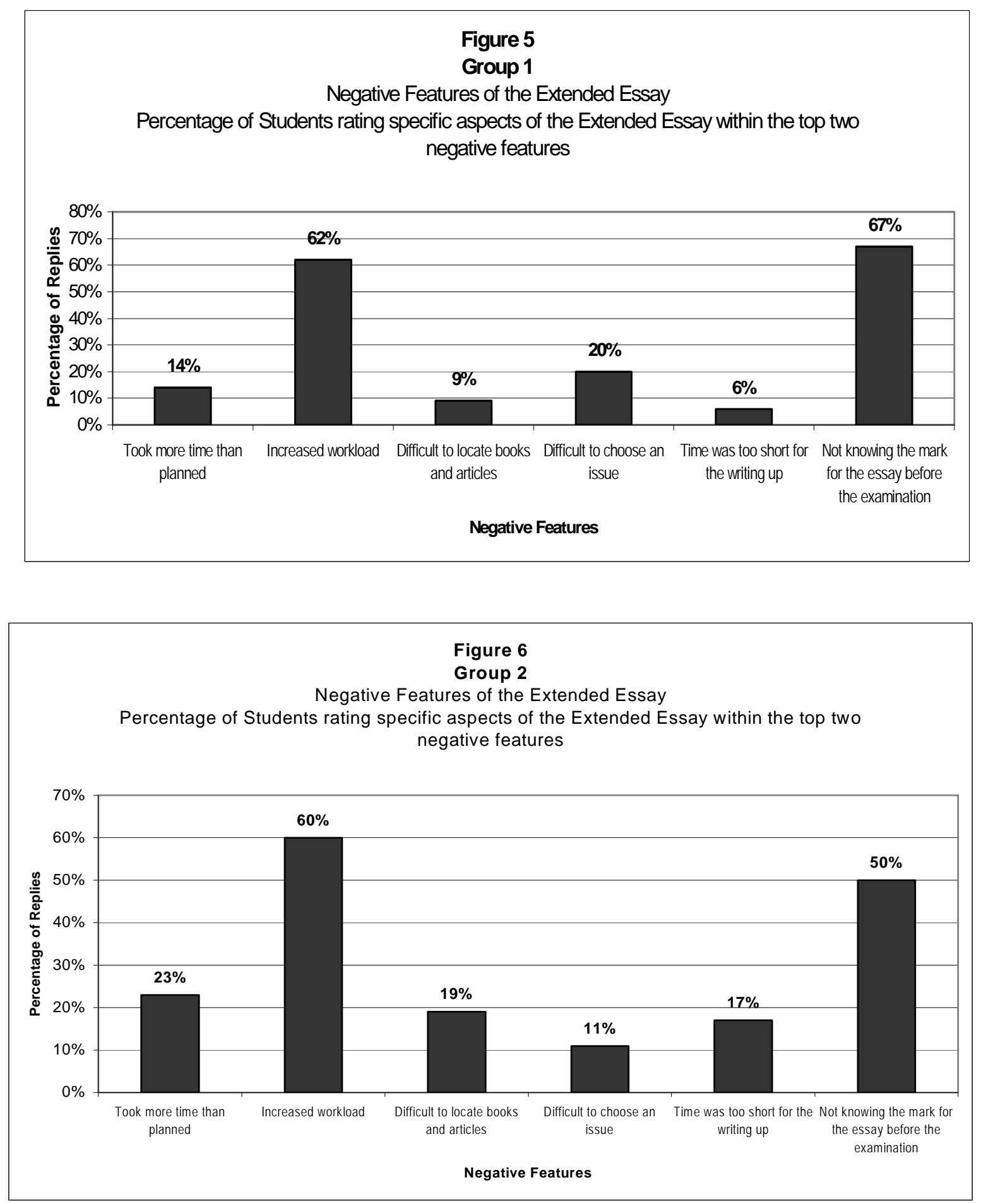
Figures 5 and 6 indicate broad agreement between both groups and in their general comments on the negative features most students expanded on the headings shown on the graphs. However, three students criticised the extended essay as a test of speed writing and English rather than History. The relatively high rating given to increased workload resulting from the extended essay may seem a statement of the obvious, but it must be viewed in a more general context. It corresponds to concerns raised by teachers that the task places additional expectations on students per se and in comparison with other subjects. Moreover, the essay operates within an overall structure which places considerable assessment demands on students with internal assessment of course units and an external examination for the whole course. It is also important to emphasise that workload and other concerns did not outweigh student perception of the overall benefits gained through the extended essay.

Many students commented that a further advantage of the essay lay in the help it provided in examination preparation. More specifically, they pointed out that if the topic chosen for the extended essay was similar to any of the essays in Paper 1 in the examination then a clear advantage had been gained. By way of contrast, many teachers argued that this was a disadvantage since it unfairly benefited some students. It must be remembered that there is a gap of almost two months between the extended essay and the examination and the actual performance in the examination, as discussed later in this article, does not bear out these concerns. 


\section{Reports of Examining Teams and the Grades Awarded}

Teachers and their students were in broad agreement over the advantages and disadvantages of the extended essay and its retention. Further support for the extended essay came in reports of the examining teams.(15) In his report on candidate performance in 2000 the Principal Assessor for Higher History noted:

“... strong evidence of careful planning and preparation and, on the part of many candidates, considerable effort in researching their chosen issues. This care was reflected in sound essay technique, with pleasing improvements in the use of conclusions and, especially, introductions. Markers also reported that, even in average scripts, there were good signs of awareness of historical debate and of historians' views. Some candidates used quotations judiciously to support their arguments, though others inserted trivial quotations to no obvious purpose".

Similar observations were contained in my report on Intermediate 2:

"Most candidates showed clear mastery of the basic essay structure with the best essays laid out with an introduction, development and conclusion. In these essays the introduction was used to refer to the question and set it within the relevant historical context. A good development contained detailed evidence relating to the issue or question with the conclusion used to sum up key points and argue for and against the key issue/s".

One essay illustrates the very high standard achieved by some candidates. The title, 'Bismarck's contribution to the unification of Germany has been over-rated. Discuss', set the stage for an analytical rather than a narrative exposition. The candidate included with the essay a list of sources and the plan. The essay ran to seven pages and had a clear, logical structure with an introduction, development and conclusion. In the introduction the candidate raised key questions and set the issue in context. The development discussed the main factors leading to unification 
alongside an evaluation of Bismarck's role. A very strong conclusion came to an overall judgement:

"In conclusion, Bismarck acted as a catalyst to the unification of Germany as he clearly did not fashion unity alone, but instead, capitalised on the socioeconomic advances already established to create advantageous solutions: if he played his hand with great skill, it was a good one in the first place".

This opening sentence from the conclusion captures the general standard of the essay which was awarded full marks. It is important to remember that it was written by a 17 year old student.

Regrettably, every essay does not reach this standard, but the marks awarded indicate that most students gain their highest marks in this part of the external assessment. In the 2001 examination at Intermediate 2 the mean grade for the extended essay was one grade higher (B) than for the examination paper (C). The improved performance in the extended essay results from the nature of the task, but is an accurate reflection of overall ability since the procedures ensured that students were the sole authors.

Nevertheless, these supportive evaluations must be considered in the context of three partly unresolved issues.

For Frith and Maclntosh, the balance between process and product becomes a prominent issue in the assessment of coursework.(16) Assessment of the extended essay concentrates on product and, it could be argued, excludes two components of investigative skills, namely, framing hypothesis/issues and the research stage. However, it has proved difficult to devise a satisfactory method of assessing these 
areas without incurring similar problems which arose with the Investigation, for example, penalising students for advice given when devising the hypothesis/issue. Nonetheless, the quality of the essay directly reflects the hypothesis and research. An ' $A$ ' rated essay incorporates a sound hypothesis and a research-based development, neither of which can be divorced from the product. Assessing the product implicitly assesses the process. Moreover, the essay only forms one part of external assessment which includes document-based questions examining the student's ability to interpret sources.

The first stage in the Investigation/extended essay involves devising an issue. As noted above, this proved problematic with many Investigations and to some extent the difficulty has continued into the extended essay. Some issues lead to descriptive and narrative essays which, per se, cannot receive high marks. Examples include:

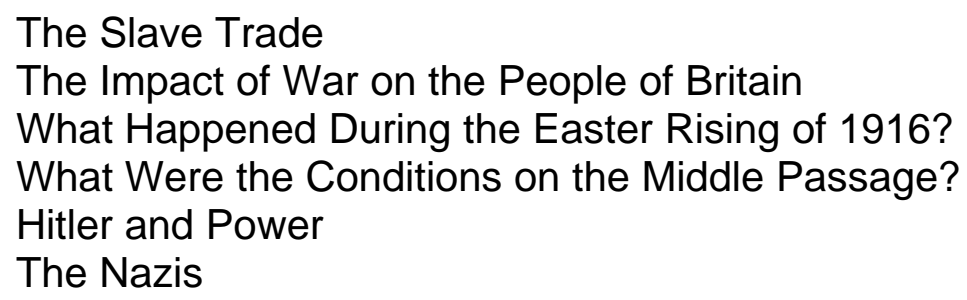

This problem persists in a minority of cases despite guidelines in the syllabus and inservice courses. One further means of guidance and support currently under discussion is a list of possible issues for each context. The list would be illustrative rather than mandatory since examining teams oppose any moves which would reduce the scope for students to devise their own hypotheses. This list would supplement the marking instructions and sample marked essays which have already been issued. 
The syllabus guidelines encourage students to use primary and secondary sources at the research stage. In practice, however, the balance is weighted heavily in favour of secondary texts. For example, the bibliography for an essay on Hitler's foreign policy listed five secondary texts and one primary; Mein Kampf. Many History textbooks contain extensive primary sources, but few students refer, for example, to census returns in studying immigration. Nevertheless, references to secondary texts provide scope for discussions on differing interpretations of key events and personalities. The restricted time available, approximately two weeks, makes it difficult extensively to study primary sources setting aside concerns over the practicalities of providing these within or outwith the classroom. It is also important to emphasise the wide use of sources throughout the course in its entirety.

\section{Conclusion}

Eckstein and Noah commented on the benefits to be gained from studying other systems of assessment:

"There are lessons to be learned from looking at different ways of doing things and the costs and benefits of each. While each set of practices is a product of a particular nation's history and circumstances, together they can provide informative exemplars of alternative arrangements".(17)

The Scottish exemplar illustrates how the desirable and the practical often come into conflict in education. Investigative skills demand active involvement in working as a historian from hypothesis and research through to a presented conclusion. The assessment of coursework, however, raises important issues relating to authenticity, fairness and workload which take on greater significance if it becomes 
a determinant of a student's final grade. It could be argued that Scotland has compromised between the desirable and the practical in devising a format which allows students to engage in research, but ensures that the resultant essay is produced under controlled conditions. The looser arrangements associated with the Investigation eroded confidence in the final grade. An assessment and examination system without public confidence has little value.

Macintyre and Barcan traced the declining popularity of History in Australia.(18) History has held its position in Scotland as witnessed in a slight increase in presentation at Higher Grade and Standard Grade since 1995. However, it faces increasing competition from 'new' subjects such as Psychology and Media Studies. The extended essay has proved a popular and successful innovation: "Very good - a worthwhile exercise", commented one student. History will need all its successes if it is to hold, let alone enhance, its position in the years to come. 


\section{References}

1. Peter Hillis, "Tempered by the Reality of the Classroom: Changes in Investigative Approaches in the Teaching of History in Scottish Schools", The History Teacher, 42, (November, 1997), 117.

2. Mary Price, "History in Danger", Teaching History, 179, (1968), 8.

3. John Fairley, Patch History and Creativity, (London, Longman, 1967), 7.

4. Stuart Macintyre, "Critical Dialogue. The Genie and the Bottle: Putting History Back Into the School Curriculum", Australian Journal of Education, 41, August, 1997, 189.

5. Ibid.

6. See for example, Alternative Ordinary Grade History, (Dalkeith, Scottish Examinations Board, 1970), 153.

7. Eric Rothschild, "The Impact of the Document Based Question on the Teaching of United States history, "The History Teacher, 33, (August, 2000), 495.

8. John Stovel, "Document Analysis as a Tool to Strengthen Student Writing", The History Teacher, 33, (August, 2000), 50.

9. Max Eckstein and Harold Noah, Secondary School Examinations, International Perspectives on Policy and Practice, (New Haven, Yale University Press, 1993), 227.

10. D.S. Frith and H.G. Maclntosh, A Teacher's Guide to Assessment, (Cheltenham, Stanley Thornes, 1984), 111.

11. Ibid., 108.

12. Robert Wood, Assessment and Learning, (Cambridge, Cambridge University Press, 1991), 134.

13. Ibid., 132.

14. Ibid., 66.

15. Reports of Principal Assessors, (Dalkeith, Scottish Qualifications Authority, 2000). See also http.www.sqa.org.uk

16. D.S. Frith and H.G. MacIntosh, A Teacher's Guide to Assessment, 111.

17. Max Eckstein and Harold Noah, Secondary School Examinations, 225.

18. Stuart Maclntyre, "Critical Dialogue. The Genie and the Bottle: Putting History Back Into the School Curriculum" and Alan Barcan, "History in a Pluralistic Culture", Australian Journal of Education, 41, August, 1997, 1999. 